\title{
ON TREES AS STAR COMPLEMENTS IN REGULAR GRAPHS
}

\author{
Peter Rowlinson \\ Mathematics and Statistics Group \\ Division of Computing Science and Mathematics \\ Scotland FK9 4LA, United Kingdom \\ e-mail: p.rowlinson@stirling.ac.uk
}

\begin{abstract}
Let $G$ be a connected $r$-regular graph $(r>3)$ of order $n$ with a tree of order $t$ as a star complement for an eigenvalue $\mu \notin\{-1,0\}$. It is shown that $n \leq \frac{1}{2}(r+1) t-2$. Equality holds when $G$ is the complement of the Clebsch graph (with $\mu=1, r=5, t=6, n=16$ ).
\end{abstract}

Keywords: eigenvalue, regular graph, star complement, tree.

2010 Mathematics Subject Classification: 05C50.

\section{REFERENCES}

[1] F.K. Bell and P. Rowlinson, On the multiplicities of graph eigenvalues, Bull. Lond. Math. Soc. 35 (2003) 401-408. doi:10.1112/S0024609303002030

[2] J. Capaverde and P. Rowlinson, Eigenvalue multiplicity in quartic graphs, Linear Algebra Appl. 535 (2017) 160-170. doi:10.1016/j.laa.2017.08.023

[3] N.E. Clarke, W.D. Garraway, C.A. Hickman and R.J. Nowakowski, Graphs where star sets are matched to their complements, J. Combin. Math. Combin. Comput. $\mathbf{3 7}$ (2001) 177-185.

[4] D. Cvetković, M. Doob, I. Gutman and A. Torğasev, Recent Results in the Theory of Graph Spectra (North-Holland, Amsterdam, 1988).

[5] D. Cvetković, P. Rowlinson and S.K. Simić, An Introduction to the Theory of Graph Spectra (Cambridge University Press, Cambridge, 2010).

[6] P. Rowlinson, Eigenvalue multiplicity in cubic graphs, Linear Algebra Appl. 444 (2014) 211-218.

doi:10.1016/j.laa.2013.11.036 
[7] P. Rowlinson, An extension of the star complement technique for regular graphs, Linear Algebra Appl. 557 (2018) 496-507.

doi:10.1016/j.laa.2018.08.018

[8] P. Rowlinson, Eigenvalue multiplicity in regular graphs, Discrete Appl. Math. 269 (2019) 11-17.

doi:10.1016/j.dam.2018.07.023

[9] P. Rowlinson and B. Tayfeh-Rezaie, Star complements in regular graphs: Old and new results, Linear Algebra Appl. 432 (2010) 2230-2242.

doi:10.1016/j.laa.2009.04.022

Received 4 February 2019

Revised 7 August 2019

Accepted 8 August 2019 